\title{
SOSIALIASI SKRINING FITOKIMIA EKSTRAK ETANOL UMBI BAWANG MERAH (Allium cepa L.)
}

\author{
Ahmad Syukur Hasibuan ${ }^{1 *}$, Vicky Edrianto ${ }^{1}$ \\ ${ }^{1}$ Fakultas Farmasi, Institut Kesehatan Medistra Lubuk Pakam \\ JIn. Sudirman No.38 Lubuk Pakam, Kabupaten Deli Serdang, \\ Sumatera Utara - Indonesia \\ *email korespondensi author: syukurhasibuan18@gmail.com
}

DOI $10.35451 /$ jpk.v1i1.732

\begin{abstract}
Abstrak
Bawang merah (Allium cepa L) banyak mengandung senyawa aktif yang memiliki efek farmakologi. Etanol adalah pelarut yang mempunyai universal dan netral, absorbsi baik, tidak beracun dan stabil sehingga dapat digunakan untuk ekstraksi umbi bawang merah. Proses Skrining fitokimia dapat mengetahui golongan senyawa metabolit sekunder yang ada pada EEUBM. Penelitian ini dilakukan ekstraksi menggunakan metode maserasi selama 5 hari dan dilanjutkan dengan remaserasi selama 2 hari. Kemudian ekstrak yang didapat dilakukan skrining fitokimia. Hasil skrining fitokimia umbi bawang merah menggunakan pelarut etanol mendapati adanya senyawa flavonoid, tanin, saponin, alkaloid dan steroid/terpenoid. Sosialiasasi hasil skrining EEUBM tersebut dilakukan terhadap mahasiswa pada saat pengajaran di kelas menggunakan aplikasi zoom.
\end{abstract}

Kata Kunci: Umbi bawang merah; Skrining Fitokimia;Etanol

\begin{abstract}
Shallots (Allium cepa L) contain many active compounds that have pharmacological effects. Ethanol is a universal solvent and has neutral, good absorption, non-toxic and stable properties so that it can be used for the extraction of shallot bulbs. Phytochemical screening was carried out to determine the class of compounds contained in the shallot tuber extract. This research was carried out with the extraction using the maceration method for 5 days and followed by remaceration for 2 days. Then the extract obtained was carried out by phytochemical screening. The results of phytochemical screening of shallot bulbs using ethanol solvent showed the presence of flavonoids, tannins, saponins, alkaloids and steroids / terpenoids. The socialization of the ethanol extract screening results of shallot bulbs was carried out to students during class teaching with zoom.
\end{abstract}

Keywords: shallot bulbs; phytochemical screening; ethanol

\section{Pendahuluan}

Indonesia adalah negara yang terdiri dari kurang dari $65 \%$ perairan dan $35 \%$ daratan dengan iklim tropis, dan dapat ditumbuhi berbagai tanaman dan dimanfaatkan sebagai pengobatan. Salah satu tamanan yang dimaksud adalah bawang merah (Allium cepa L) yang merupakan herba tahunan dari famili Liliaceae yang banyak tumbuh hampir di seluruh penjuru dunia (Sasmito, 2017).
Bawang merah biasanya dijadikan sebagai penyedap rasa pada makanan atau bumbu masak dan berkhasiat berbagai macam khasiat obat (Octaviani et al., 2019). Mengandung senyawa metabolit sekunder seperti flavonoid, kaemferol, flavonglikosida, fluroglusin, dihidroaliin, sikloaliin, metialiin, kuersetin, polifenol, sulfur pada umbi bawang merah (Utami, 2013) Senyawa tersebut mempunyai aktivitas farmakologi, yaitu flavonoid dalam mencegah katarak, jantung dan kanker (Arora et al., 2017), tanin sebagai antioksidan, antibakteri dan 
Received: 08 June 2021 :: Accepted: 26 June 2021 :: Published: 30 June 2021

antijamur (Octaviani et al., 2019), serta saponin pada gangguan batuk sebagai pengencer dahak (Rahayu dan Nur, 1996).

Pengambilan sari senyawa kimia yang terkandung di dalam umbi bawang merah diperlukan ekstraksi dengan menggunakan pelarut dan metode yang tepat (Emelda, 2019).

Skrining fitokimia dilakukan untuk mengetahui ada atau tidaknya senyawa yang merupakan metabolit sekunder pada tumbuhan (Purwati et al., 2017). Pada penelitian ini dilakukannya skrining fitokimia untuk melihat golongan senyawa yang terkandung pada umbi bawang merah sehingga dapat diketahui kemampuan pelarut etanol dalam menarik senyawa yang terkandung dalam EEUBM.

\section{Metode}

\subsection{Bahan Penelitian}

Umbi bawang merah diperoleh dari pedagang di Rantauprapat, SUMUT, Indonesia. Pelarut yang digunakan adalah etanol 96\%. Bahan-bahan yang digunakan adalah asam klorida $(\mathrm{HCl})$ pekat $2 \mathrm{~N}$, amil alkohol, kalium iodida (KI), iodium $\left(\mathrm{I}_{2}\right)$, raksa (II) klorida $\left(\mathrm{H}_{\mathrm{g}} \mathrm{Cl}_{2}\right)$, asam nitrat $\left(\mathrm{HNO}_{3}\right) \quad 0,5 \mathrm{~N}$, kloroform, asam sulfat $\left(\mathrm{H}_{2} \mathrm{SO}_{4}\right)$ pekat $2 \mathrm{~N}$, asam asetat anhidrida, aquadest, besi (III) klorida $\left(\mathrm{FeCl}_{3}\right) 1 \%$, pereaksi Mayer, pereaksi Dragendorff, pereaksi Bouchardat.

\subsection{Alat Penelitian}

Alat-alat yang digunakan dalam penelitian ini meliputi batang pengaduk, pipet tetes, aluminium foil, penjepit tabung, tabung reaksi, gelas ukur, timbangan analitik, beaker glass, waterbath, kertas saring, sendok tanduk, kertas perkamen, rak tabung reaksi.

\subsection{Prosedur Pelaksanaan Pengabdain 2.3.1 Metode Demonstrasi}

Sampel yang digunakan adalah umbi bawang merah yang diperoleh dari pedagang bawang merah di Pasar Gelugur Rantauprapat, Kecamatan Rantau Utara, Kabupaten Labuhanbatu, Sumatera Utara pada bulan Februari 2020. Sampel yang diperoleh kemudian dikumpulkan lalu dicuci bersih dan dirajang lalu dikeringkan dilemari pengering bersuhu $40^{\circ} \mathrm{C}$, kemudian dilakukan penggilingan hingga didapatkan serbuk umbi bawang merah dan ditimbang lalu disimpan pada tempat yang tertutup rapat. Setelah dilakukan penyiapan sampel, sosisalisasi dilakukan melalui media aplikasi zoom.

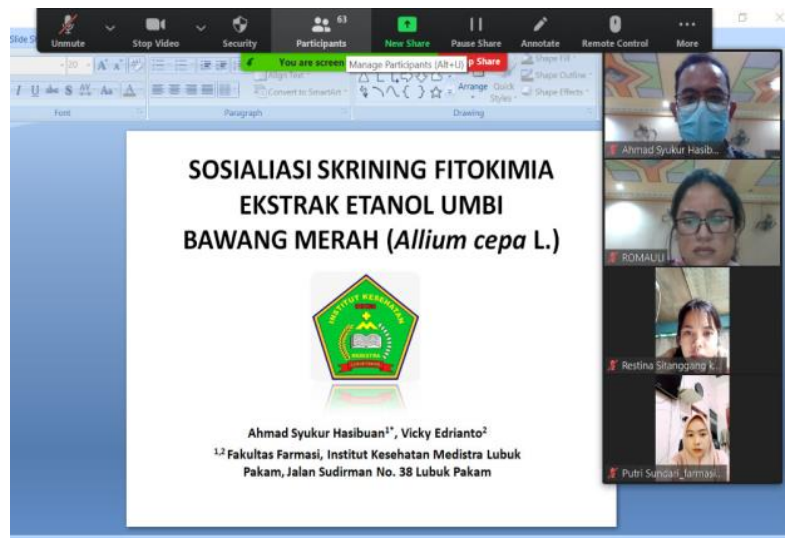

Gambar 1. Pelaksanaan sosialisasi

\subsubsection{Pembuatan EEUBM}

Sebanyak 1000 gram serbuk simplisia umbi bawang merah dimasukan kedalam wadah maserasi, lalu dilarutkan dalam 75 bagian etanol sebanyak 7,5 L. Ditutup dan dibiarkan selama 5 hari terlindung dari cahaya sambil sesekali diaduk. Setelah 5 hari sampel disaring, setelah itu ampas yang disaring dimaserasi kembali dengan pelarut 25 bagian etanol sebanyak 2,5 L hingga diperoleh seluruh pelarut 10 liter. Lalu didiamkan selama 2 hari. Maserat diuapkan menggunakan rotary evaporator pada suhu $70^{\circ} \mathrm{C}$ sampai didapatkan bentuk ekstrak kental (Ditjen POM, 1979).

\subsubsection{Skrining Fitokimia EEUBM}

Skrining fitokimia pada EEUBM diantaranya dilakukan pemeriksaan senyawa flavonoid, saponin, tanin, alkaloid dan steroid/triterpenoid.

\section{a. Pemeriksaan flavonoid}

Diambil sampel 0,5 gram simplisia kemudian ditambahkan $10 \mathrm{ml}$ aquadest panas, didihkan selama 10 menit dan disaring dalam keadaan panas, filtrat yang diperoleh kemudian diambil $5 \mathrm{ml}$ lalu ditambahkan 0,1 gram serbuk $\mathrm{Mg}$ dan 1 $\mathrm{ml}$ asam klorida $(\mathrm{HCl})$ pekat dan $2 \mathrm{ml}$ amil alkohol, dikocok dan dibiarkan memisah. Flavonoid positif jika terjadi warna merah, kuning, jingga, pada lapisan amil alkohol (Depkes, 1989).

b. Pemeriksaan tanin 
$====================================================+1$
Received: 08 June 2021 :: Accepted: 26 June 2021 :: Published: 30 June 2021

Diambil sampel sebanyak 0,5 gram lalu dilarutkan dengan $10 \mathrm{ml}$ aqudest, kemudian disaring menggunakan kertas saring. Selanjutnya filtrat yang diperoleh diambil sebanyak $2 \mathrm{ml}$ kemudian ditambahkan 2 tetes pereaksi $\mathrm{FeCl}_{3} 1 \%$. Jika Terbentuk warna biru atau hijau kehitaman menunjukan adanya tanin (Harborne, 1987).

c. Pemeriksaan steroid/triterpenoid
Diambil sampel sebanyak 1 gram lalu ditambahkan $20 \mathrm{ml}$ kloroform dan diletakkan didalam tabung reaksi yang kering, kemudian ditambahkan pereaksi Liebermann Burchard (asam asetat anhidrat dan asam sulfat pekat). Reaksi positif akan ditunjukkan dengan adanya cincin berwarna jingga/ ungu untuk triterpenoid dan steroid dengan warna hijau kebiruan (Harborne, 1987).

Tabel 1. Hasil skrining fitokimia EEUBM

\begin{tabular}{|c|c|c|c|}
\hline No & $\begin{array}{c}\text { Uji } \\
\text { Fitokimia }\end{array}$ & Hasil Skrining Fitokimia & Kesimpulan \\
\hline 1. & Flavonoid & Merah hingga Jingga & $(+)$ \\
\hline 2. & Saponin & Terbentuk busa setinggi $1-10 \mathrm{~cm}$ selama $<10$ detik & $(+)$ \\
\hline 3. & Tanin & Hijau kehitaman & $(+)$ \\
\hline \multirow{3}{*}{4.} & \multirow{3}{*}{ Alkaloid } & Dengan pereaksi Mayer terbentuk endapan kuning & $(+)$ \\
\hline & & $\begin{array}{c}\text { Dengan pereaksi Dragendorf terbentuk endapan } \\
\text { jingga }\end{array}$ & $(+)$ \\
\hline & & $\begin{array}{c}\text { Dengan pereaksi Bouchardat terbentuk endapan } \\
\text { coklat }\end{array}$ & $(+)$ \\
\hline \multirow{2}{*}{5.} & Steroid & Cincin Hijau & $(+)$ \\
\hline & Triterpenoid & Cincin Ungu & $(+)$ \\
\hline
\end{tabular}

Keterangan: $(+)$ positif = mengandung golongan senyawa

$(-)$ negatif $=$ tidak mengandung golongan senyawa

\section{Hasil Dan Pembahasan}

Berbagai jenis tumbuhan telah dimanfaatkan oleh masyarakat Indonesia secara turun temurun untuk mencegah maupun mengobati berbagai jenis penyakit (Emelda, 2019). Bawang merah adalah salah satu tumbuhan yang memiliki berbagai kandungan yang sangat penting dalam menjaga kesehatan tubuh (Rahayu dan Nur, 1996).

Pembuatan EEUBM dilakukan dengan metode maserasi (menggunakan pelarut sesuai dengan cara mengocoknya beberapa kali atau mengaduknya pada suhu kamar/ temperatur dan terlindungi dari cahaya)(Depkes RI, 2000). Metode ini dilakukan karena dianggap paling sederhana di antara metode ekstraksi (Emelda, 2019). Maserasi harus dilakukan pengocokan berulang-ulang untuk menjaga kestabilan konsentrasi bahan ekstraksi yang lebih cepat didalam cairan.

Cairan penyari (pelarut) yang digunakan dalam penelitian ini adalah etanol $96 \%$. Hasil positif dalam pengujian skrining fikomia umbi bawang merah menunjukan adanya flavonoid, saponin, tanin, alkaloid dan steroid/triterpenoid yang dapat dilihat pada Tabel 1 .

Hasil iji flavonoid yang dilakukan pada EEUBM menunjukkan hasil positif mengandung flavonoid, pengujian ekstrak menggunakan $\mathrm{HCl}$ pekat dan serbuk magnesium akan terbentuk perubahah menjadi warna merah pada lapisan amil alkohol. Penambahan serbuk $\mathrm{Mg}$ bertujuan agar terbentuk ikatan antara gugus karbonil pada senyawa flavonoid sedangkan penambahan $\mathrm{HCl}$ agar terjadi pembentukan garam flavilium dengan perubahan warna merah jingga (Andriyanto et al., 2016).

Hasil uji saponin dilakukan dengan cara memanaskan ekstrak yang telah ditambahkan dengan aquadest hingga mendidih selama kurang dari 10 menit, setelah dingin dilakukan pengocokan sampai terbentuk busa, lalu ditambahkan $\mathrm{HCl} 2 \mathrm{~N}$. Hasil yang didapatkan menunjukkan bahwa adanya kandungan saponin pada EEUBM. Busa yang terdapat pada hasil uji merupakan glikosida yang terhidrolisis menjadi glukosa dan senyawa 
Received: 08 June 2021 :: Accepted: 26 June 2021 :: Published: 30 June 2021

lain sehingga membentuk buih (Marliana et al., 2005).

Hasil uji tanin dengan reagen $\mathrm{FeCl} 3$ $1 \%$ yang ditambahkan pada EEUBM menunjukkan hasil positif, hal ini ditandai dengan menghasilkan warna hijau kehitaman. Tanin yang terkandung dalam akan ekstrak bereaksi dengan ion $\mathrm{Fe}^{3+}$ dari pereaksi sehingga membentuk senyawa kompleks (Harborne, 1996).

Hasil uji alkaloid pada EEUBM mengandung senyawa alkaloid, hal ini diketahui berdasarkan saat ditetesi dengan reagen Mayer menghasilkan endapan kuning. Nitrogen pada alkaloid akan membentuk kompleks kaliumalkaloid yang mengendap kareana adanya reaksi antara ion logam $\mathrm{K}^{+}$dari kalium tetra iodomerkurat(II) (Marliana et al., 2005).

Hasil uji steroid/ triterpenoid pada EEUBM dinyatakan positif mengandung senyawa steroid dan triterpenoid, hal ini ditandai dengan terbentuknya cincin hijau dengan menggunakan pereaksi kloroform $\left(\mathrm{CHCl}_{3}\right)$ dan larutan uji LiebermenBurchard (larutan anhidrida asetat dan asam sulfat pekat) untuk adanya steroid dan cincin ungu untuk adanya senyawa triterpenoid. Hal ini didasari pada senyawa triterpenoid yang terbentuk dan steroid membentuk warna oleh $\mathrm{H}_{2} \mathrm{SO}_{4}$ dalam pelarut asam asetat anhidrid.Perbedaan warna yang dihasilkan oleh triterpenoid dan steroid disebabkan perbedaan gugus pada atom C-4 (Habibi et al., 2018).

Pelaksanaan sosisaliasasi hasil skrining kepada mahasiswa dilakukan dengan metode pengajaran melalui metode aplikasi zoom untuk media aplikasi pembelajraran.

\section{Kesimpulan}

Hasil skrining fitokimia EEUBM menggunakan pelarut etanol $96 \%$ diketahui positif mengandung golongan senyawa seperti flavonoid, saponin, tanin, alkaloid dan steroid/ triterpenoid.

\section{Ucapan Terimakasih}

Rinaldo Berutu selaku laboran laboratorium Fitokimia di Jurusan Farmasi Fakultas Farmasi Institut Kesehatan Medistra Lubuk Pakam atas bantuan, saran , serta motivasi yang telah diberikan kepada peneliti.

\section{Daftar Pustaka}

Andriyanto, B. E., Ardiningsih, P., \& Idiawati, N. 2016. Skrining Fitokimia Ekstrak Daun Belimbing Hutan (Baccaurea angulata Merr.). Jurnal Kimia Khatulistiwa, 5(4).

Arora, E. K., Sharma, V., Khurana, A., Manchanda, A., Sahani, D. K., Abraham, S., ... \& Gupta, H. 2017. Phytochemical analysis and evaluation of antioxidant potential of ethanol extract of Allium cepa and ultra-high homoeopathic dilutions available in the market: $A$ comparative study. Indian Journal of Research of Homopoeopathy, 11(2): 89-94.

Depkes RI. 1989. Materia Medika Indonesia Jilid V. Jakarta: Depkes RI.

Depkes RI. 2000. Parameter Standar Umum Ekstrak Tumbuhan Obat. Jakarta: Direktorat Jenderal Pengawas Obat dan Makanan.

Dijen POM. 1986. Sediaan Galenik. Jakarta: Depkes RI.

Ditjen POM. 1979. Farmakope Indonesia Edisi III. Depkes RI.

Ditjen POM. (1995). Farmakope Indonesia Edisi IV. Depkes RI.

Emelda. 2019. Farmakognosi : Untuk Mahasiswa Kompetensi Keahlian Farmasi. Yogyakarta: Pustaka Baru Press.

Harborne, J. B. 1987. Metode Fitokimia Penuntun Cara Modern Menganalisa Tumbuhan. Bandung: Penerbit ITB.

Kristanti, A. N., N. S. Aminah, M. Tanjung, dan B. Kurniadi. 2008. Buku Ajar Fitokimia. Surabaya: Airlangga University Press.

Marliana, S.D., Suryanti, V., \& Suyono. 2005. Skrining Fitokimia dan Analisis Kromatografi Lapis Tipis Komponen Kimia Buah Labu Siam (Sechium edule Jacq. Swartz.) dalam Ekstrak Etanol. Biofarmasi, 3 (1): 26-31.

Octaviani, M., Fadhli, H., \& Yuneistya, E. 2019. Uji Aktivitas Anti mikroba Ekstrak Etanol Kulit Bawang Merah (Allium cepa L.) dengan Metode Difusi Cakram. Pharmaceutical Sciences \& Research, 6(1), 8. 
Received: 08 June 2021 :: Accepted: 26 June 2021 :: Published: 30 June 2021

Purwati, S., Lumowa, S. V., \& Samsurianto, S. (2017. Skrining Fitokimia Daun Saliara (Lantana Camara L) Sebagai Pestisida Nabati Penekan Hama Dan Insidensi Penyakit Pada Tanaman Holtikultura di Kalimantan Timur. In Prosiding Seminar Kimia. 153158.

Rahayu, E. dan Nur B. V. A. 1996. Bawang Merah. Jakarta: Penebar Swadaya.

Sasmito, E. 2017. Imunomudulator Bahan Alami. Yogyakarta: Rapha Publishing.

Utami, P., Lina., M., \& Tim, P., PS. 2013. Umbi Ajaib Tumpas Penyakit. Jakarta: Penebar Swadaya.

Voight, R. 1994. Buku Pengantar Teknologi Farmasi. Yogyakarta: Universitas Gadjah Mada Press. 